\title{
Engineering Properties of Polyethylene Terephthalate Fibre Reinforced Concrete with Fly Ash as a Partial Cement Replacement
}

\author{
Rebecca Belay Kassa ${ }^{1^{*}} \quad$ Christopher Kanali ${ }^{2} \quad$ Nathaniel Ambassah ${ }^{3}$ \\ 1. MSc. Civil Engineering Student, Pan African University (PAU), Jomo Kenyatta University of \\ Agriculture \& Technology (JKUAT), Nairobi, Kenya \\ 2. Professor, Department of Agricultural and Biosystems Engineering, Jomo Kenyatta University of \\ Agriculture \& Technology (JKUAT), Nairobi, Kenya \\ 3. PhD, Department of Civil Engineering, Jomo Kenyatta University of Agriculture \& Technology
}

(JKUAT), Nairobi, Kenya

This research is funded by African Union Commission (AUC) and Japan International Cooperation Agency (JICA)

Abstract

Although concrete has good qualities that make it suitable for a wide range of applications in the construction industry, it also has undesirable properties; one of which is its low tensile strength. Numerous studies are being carried out to improve the undesirable features of concrete by using substitute materials such as industrial, manufacturing, agricultural as well as domestic wastes. In Africa, there is a pressing need for reusing and recycling waste materials. Following the extensive use of concrete in the vast construction industry, the incorporation of wastes like Polyethylene Terephthalate (PET) bottles and fly ash to improve its quality is a sensible intervention. PET bottles, used for packaging of beverages, and fly ash, generated during the combustion of coal, are causing severe environmental degradation. This study evaluated the effects of using PET fibres and fly ash on the performance of concrete. PET fibres with an aspect ratio of $50(100 \mathrm{~mm}$ length and $2 \mathrm{~mm}$ width) were incorporated in the concrete mix at percentages of $0.5,1.0$ and $1.5 \%$ by weight of cement. On the other hand, fly ash was introduced as a cement replacement at percentages of $20,22.5,25,27.5$ and $30 \%$ by weight of cement. The performance of the modified concrete was evaluated based on workability, compressive strength, and splitting tensile strength. The combination of $1.5 \%$ PET fibres and $27.5 \%$ fly ash resulted in $33.45 \%$ tensile strength improvements, while keeping the workability and compressive strength unaffected.

Keywords: Concrete, polyethylene terephthalate; fly ash; ordinary Portland cement; aggregates; workability; compressive strength; splitting tensile strength; aspect ratio

DOI: $10.7176 / \mathrm{CER} / 11-6-05$

Publication date:July $31^{\text {st }} 2019$

\section{Introduction}

Concrete has incredible qualities that make it suitable for a wide range of applications in the construction industry. Its high compressive strength, durability, fire resistance, low maintenance and its ability to be cast into any desired shape are among its desirable properties. Regardless of these advantageous properties, concrete also has detrimental behaviours like low tensile strength and its heavy weight. Irrespective of this fact, with the rapid population growth in the world, there is an increasing demand for the expansion of infrastructure in the construction industry. This increases the consumption of concrete in an exponential rate (Kosmatka, 2011). Studies are being carried out to improve the undesirable properties of concrete by looking for relatively cheap and easily available substitute materials such as industrial, manufacturing, agricultural as well as domestic wastes.

Solid waste disposal like plastic bottle waste has been a pressing environmental issue in most African countries as they are contributing to the severe degradation of the environment. Polyethylene Terephthalate (PET) bottles are conventional plastic bottles that currently are highly utilised. They are used to package water, soft drinks, liquid foods, and various other beverages. With their increasing demand, their disposal is becoming difficult. According to Van den Berg (2014), their worldwide consumption was predicted to reach 19.1 million tons by 2017 with an increase of $5.2 \%$ per annum. However, out of all these only $18-20 \%$ of this is recycled. The remaining 15.5 million tons of un-decomposable PET bottles are left out exposed to the environment. According to Standard Media (2018), Kenya PET Recycling Company Limited stated that in Kenya about 20,000 tons of PET are generated annually and only 1,000 tons $(5 \%)$ is recycled. The degradation of waste PET bottles takes a very long time in nature (more than a hundred years) (Akçaözoğlu et al., 2010). Waste PET bottles have several harmful effects on water, soil, air, vegetation as well as human and animal health in addition to their aesthetically unpleasing appearance and disruption of the ecological cycle. Different studies have been carried out to see whether or not these waste materials can be used in other industrial areas. The construction industry is an 
appropriate candidate with its high consumption ability. This will be a decent alternative for clearing and protecting the environment from waste plastic bottles (Saini et al., 2016). One of the methods of using waste PET bottles in the construction industry is as PET fibre to produce fibre reinforced concrete. This helps improve ductility, tensile strength, flexural strength (because of the sewing effect that they have) and thermal insulation of concrete (Fraternali et al., 2011). However, studies show that the addition of PET fibres in concrete also shows a decrement in its compressive strength and workability (Namakula, 2017).

Fly ash is produced on combustion of coal for energy generation. Coal has been fuelling and will continue fuelling the principal segment of the international electric power production. This has greatly increased the demand for coal consumption and in turn the production of fly ash (Yao et al, 2015). The annual worldwide generation of fly ash is around 750 million tons (Blissett and Rowson, 2012; Izquierdo and Querol, 2012). The application of fly ash in concrete as a cement replacement has been found to be successful in previous studies. It showed positive effects on fresh and hardened concrete because of its pozzolanic nature. It improved concrete properties like workability, compressive strength, drying shrinkage, thermal properties and abrasion resistance (Akçaözoğlu and Atis, 2011).

This study focused on assessing the engineering properties of PET reinforced concrete containing fly ash as partial cement replacement. Properties studied include: compressive strength, tensile strength, and workability. A comparison was made between the properties of the modified concrete and the conventional one.

\section{Materials and Methods}

\subsection{Materials}

The materials used for the study include: ordinary Portland cement type I (42.5) in compliance to BS EN 197-1 (2011), fine (river sand) and coarse aggregates which were washed and air dried in accordance to BS EN 12620 (2013), a general supply tap water conforming to BS 1348-2 (1980), coal fly ash, and PET fibres obtained by collecting waste plastic bottles from the nearby surrounding. The bottles were cleaned, dried and cut into rectangular strips manually using scissors. The aspect ratio of the fibres was 50 corresponding to $100 \mathrm{~mm}$ length and $2 \mathrm{~mm}$ width.
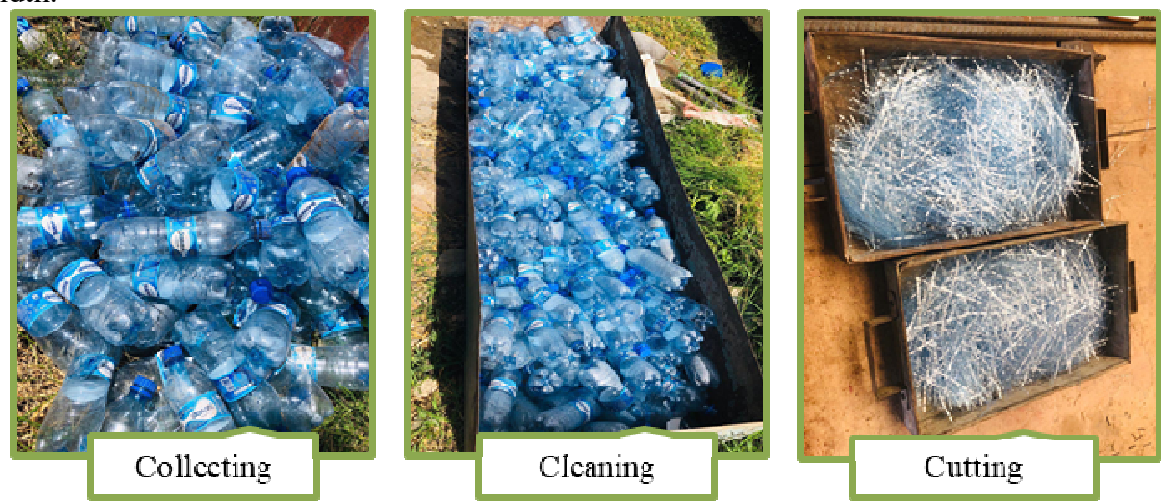

Figure 1: Preparation of PET fibres

\subsection{Methods}

2.2.1. Characterization of Constituent Materials

Table 1 shows the characterization tests that were performed on the concrete constituent materials. The procedures followed are described on the following section. 
Table 1: Characterization tests on constituent materials

\begin{tabular}{cl}
\hline Material & \multicolumn{1}{c}{ Tests } \\
\hline \multirow{3}{*}{ Coarse aggregate } & Particle size distribution \\
& Specific gravity and water absorption \\
& Moisture content \\
& Compacted bulk density and voids \\
& Aggregate Crushing Value (ACV) \\
& Aggregate Impact Value (AIV) \\
\hline \multirow{2}{*}{ Fine aggregate } & Particle size distribution \\
& Specific gravity and water absorption \\
& Moisture content \\
& Compacted bulk density and voids \\
\hline & Consistency \\
Ordinary Portland cement and fly ash & Initial and final setting time \\
& Specific gravity \\
& Chemical composition \\
\hline PET fibres & Tensile strength test \\
\hline
\end{tabular}

The aggregates were sampled according to BS EN 932-1(1997) requirements to get a representative sample. BS EN 933-1 (2012) was used as a guideline while grading the aggregates. The procedure included using test sieves that comply with BS ISO 3310-2 (2013) requirements. Specific gravity and water absorption for coarse and fine aggregates were determined following BS EN 1097-6 (2013) testing method. On the other hand, moisture content for aggregates was determined as per BS 812: Part 109 (1990). Compacted bulk density and voids were evaluated as per the requirements of BS EN 1097-3 (1998) for both fine and coarse aggregates. ACV and AIV for coarse aggregates, on the other hand, were determined as per BS 812: Part 110 (1990) and BS 812: Part 112 (1990), respectively. Consistency, and initial and final setting time test procedures for both standard cement and fly ash pastes followed BS EN 196-3 (2016). PET fibres were characterized by determining their thickness and performing a tensile strength test.

\subsubsection{Concrete Mix Design and Mixing Method}

The mix design for the control mix of $25 \mathrm{MPa}$ ordinary Portland cement concrete was prepared as per BS EN 206 (2014) and BS 8500-2 (2012) provisions. A mix ratio of 1:1.63:3.13 was taken for cement, fine and coarse aggregates, respectively. Water to cement ratio of 0.6 was used when preparing the mix. This mix design was used for the entire study only varying the percentages of plastic fibres and fly ash while assessing the engineering properties of the modified concrete. Three treatment levels $(0.5,1.0$ and $1.5 \%$ by weight of cement) were used for PET bottle fibres, the proportions of fly ash, used to replace cement, were 20, 22.5, 25, 27.5 and $30 \%$ by weight of cement.

The study was conducted in two phases. The first phase assessed the effects of PET bottle fibres on engineering properties of fresh and hardened concrete by adding $0.5,1.0$ and $1.5 \%$ fibres by weight of cement. The optimum amount of PET fibre was selected based on the tensile strength obtained. In the second phase, the selected optimum PET fibre content was kept constant while fly ash was added by replacing 20, 22.5, 25, 27.5 and $30 \%$ of cement by weight. The optimum fly ash content was selected based on workability and compressive strength performances of the concrete. The materials were mixed manually as per BS 1881-125 (2013) provisions for laboratory tests.

\subsubsection{Methods for testing Fresh and Hardened Concrete Properties}

Workability was evaluated as a fresh concrete property. A slump test was performed on three samples of each mix according to the procedures specified in BS EN 12350-2 (2009). BS EN 12350-1 (2009) was used as a guideline while sampling the specimens for the slump test.

The properties assessed on hardened concrete were compressive strength, and splitting tensile strength. Fifty-four (54) cubes with dimensions of $150 \mathrm{~mm}$ and 54 cylinders with dimensions of $150 \mathrm{~mm}$ diameter and 300mm length as per BS EN 12390-1 (2012) requirements were used for the compressive and splitting tensile strength of concrete, respectively. Three specimens were cast and cured for each mix following BS EN 12390-2 (2009) for 7 and 28 days. The specimens were loaded to failure under a universal testing machine conforming to BS EN 12390-4 (2000). BS EN 12390-3 (2009) and BS EN 12390-6 (2009) were used to determine the compressive and splitting tensile strength of concrete, respectively.

\section{Results and Discussions}

\subsection{Characterization of Constituent Materials}

a) Aggregates

The fine and coarse aggregates were characterized in terms of gradation, specific gravity, water absorption, moisture content, compacted bulk density, voids, ACV and AIV. 
The results for gradation of coarse and fine aggregates are presented in Figures 2 and 3, respectively. According to the results, it is clear that the gradation curves for both coarse and fine aggregates lie within the envelope as specified in BS 882 (1992). The nominal size of the coarse aggregates was found to be between 5 and $20 \mathrm{~mm}$. Fine aggregates, on the other hand, had a nominal size between 0.15 and $5 \mathrm{~mm}$. The fineness modulus of the fine aggregates was also found to be 2.99. BS EN 12620 (2013) states that the fineness modulus of the fine aggregates should be in the range of 2.1 to 4.0 .

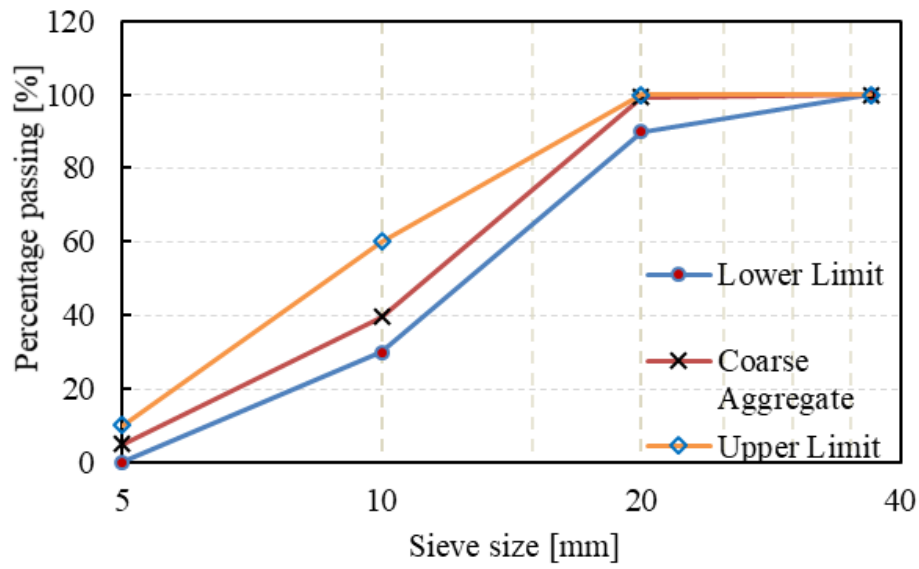

Figure 2 Coarse aggregate grading curve

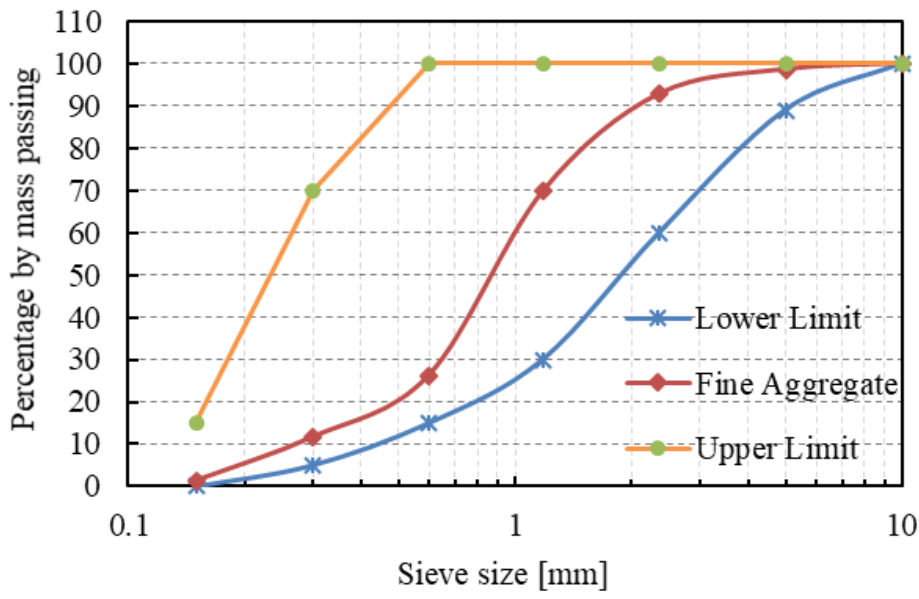

Figure 3: Fine aggregate grading curve

The results of the engineering properties of coarse and fine aggregates are presented in Table 2 .

Table 2: Engineering properties of coarse and fine aggregates

\begin{tabular}{lcc}
\hline Tests & Coarse aggregates & Fine aggregates \\
\hline Maximum particle size $(\mathrm{mm})$ & 20 & 5 \\
\hline Fineness modulus & - & 2.99 \\
\hline Bulk specific gravity on surface dried basis & 2.51 & 2.43 \\
Bulk specific gravity on oven dried basis & 2.47 & 2.40 \\
Apparent specific gravity & 2.56 & 2.47 \\
Water absorption $(\%)$ & 1.29 & 1.11 \\
Moisture content & 1.73 & 0.54 \\
Compacted bulk density $\left(\mathrm{kg} / \mathrm{m}^{3}\right)$ & 1436.87 & 1638.21 \\
Voids $(\%)$ & 33.12 & 38.57 \\
ACV (\%) & 21.57 & - \\
AIV $(\%)$ & 15.42 & - \\
\hline
\end{tabular}

b) Cement and Fly Ash

The results of the physical and chemical properties of cement and fly ash are shown in Tables 3 and 4 , respectively. The results show that it takes fly ash a longer time to set compared to cement which might be 
attributed to the fact that cement particles react faster with water than fly ash particles (Table 3). The siliceous and aluminous materials of fly ash together with water and calcium hydroxide form CSH (Table 4), cementitious products similar to Portland cement, at ambient temperatures. These pozzolanic properties of the ash, including its lime binding capacity make it useful for the manufacture of cement, building materials concrete and concreteadmixed products (Ahmaruzzaman, 2010).

Table 3: Physical properties of cement and fly ash

\begin{tabular}{lcc}
\hline Tests & Ordinary & Portland cement \\
\hline Consistency (\%) & 31.25 & 23.75 \\
Initial setting time (min) & 133 & 199 \\
Final setting time (min) & 270 & 278 \\
Specific gravity & 3.09 & 2.12 \\
\hline
\end{tabular}

Table 4: Chemical composition of cement and fly ash

\begin{tabular}{ccc}
\hline $\begin{array}{c}\text { Major Component } \\
\text { (\% by mass) }\end{array}$ & \multicolumn{2}{c}{ Chemical composition (\% by mass) } \\
\cline { 2 - 3 } $\mathrm{CaO}$ & Ordinary Portland cement & 6.36 \\
$\mathrm{SiO}_{2}$ & 61.48 & 54.57 \\
$\mathrm{Al}_{2} \mathrm{O}_{3}$ & 25.79 & 23.14 \\
$\mathrm{Fe}$ & 5.60 & 5.89 \\
$\mathrm{~S}$ & 2.34 & 0.39 \\
$\mathrm{~K}_{2} \mathrm{O}$ & 2.60 & 1.92 \\
$\mathrm{P}_{2} \mathrm{O}_{5}$ & 1.00 & 0.33 \\
$\mathrm{Cl}$ & 0.52 & - \\
$\mathrm{Ti}$ & 0.23 & 0.62 \\
$\mathrm{Sr}$ & 0.21 & - \\
$\mathrm{MgO}$ & 0.14 & 6.24 \\
$\mathrm{Ba}$ & - & 0.16 \\
\hline
\end{tabular}

c) PET Fibres

PET fibres were characterized from thickness and tensile strength perspective. Thirty samples of PET fibres were randomly selected and assessed. The results are presented in Table 5.

Table 5: Properties of PET fibres

\begin{tabular}{ll}
\hline Properties & Description \\
\hline Length $(\mathrm{mm})$ & 100 \\
Width $(\mathrm{mm})$ & 2 \\
Thickness $(\mathrm{mm})$ & 0.21 \\
Aspect ratio & 50 \\
Shape & Rectangular \\
Tensile strength $(\mathrm{MPa})$ & 84.123 \\
Colour & Colourless \\
\hline
\end{tabular}

\subsection{Fresh and Hardened Concrete Properties}

The first section presents results of the effects of adding PET bottle fibres at $0.5,1.0$ and $1.5 \%$ content by weight of cement on engineering properties of fresh and hardened concrete.

a) Workability

Workability drastically decreased with increase in the content of PET fibres in the concrete mix (Figure 4). The reduction was 50,75 , and $90 \%$ when $0.5,1.0$, and $1.5 \%$ PET fibre were added, respectively, when compared with the control mix. This shows that PET fibres affect the workability negatively. Therefore, addition of $1.5 \%$ PET fibre to concrete by weight of cement resulted in the lowest slump of $10 \mathrm{~mm}$. 


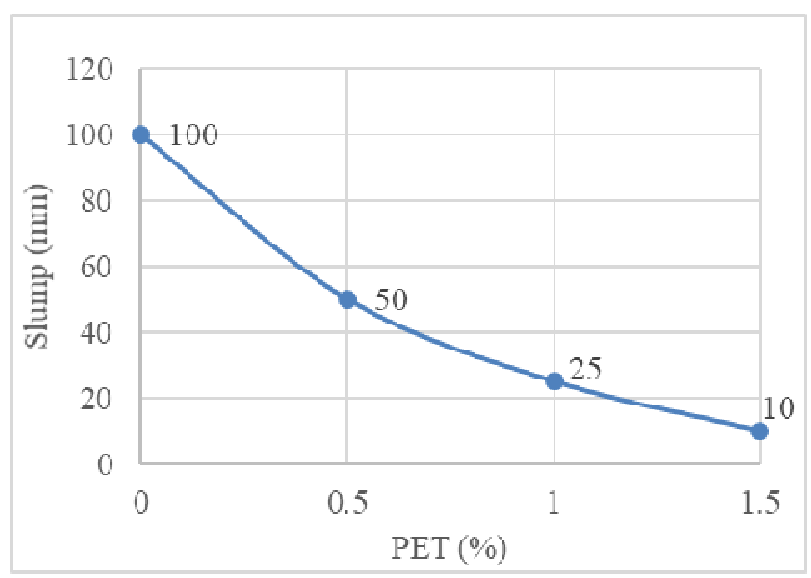

Figure 4: Slump test results of PET fibre modified concrete

The substantial reduction of slump with the addition of PET might be due to the presence of increased surface area of the fibres in the mix. Nibudey et al. (2014) reported that increased surface area of fibres causes them to adhere to other concrete ingredients making the mix less workable. This directly affects the necessary compaction effort and in turn the compressive strength.

b) Compressive Strength

The 7th and 28th day compressive strength decreased with increase in PET fibre content by weight of cement relative to the control mix (Figure 5). The lowest strength reduction of $21.236 \mathrm{MPa}$ at 28th day occurred with the addition of $1.5 \%$ of PET fibre by cement weight. Compressive strength slightly increased with the addition of $0.5 \%$ PET fibres by mass of cement. There was a considerable reduction of compressive strength by 5.74 and $14.16 \%$ on the 7 th day for 1.0 and $1.5 \%$ addition of fibre, respectively. An approximately similar reduction of compressive strength of 6.11 and $15.2 \%$, respectively, was observed on the 28 th day in comparison to the control mix.

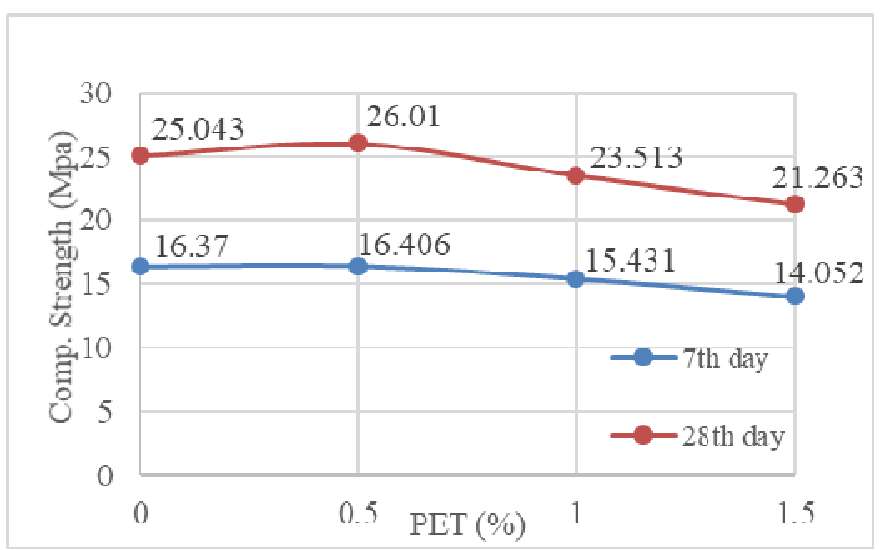

Figure 5: Compressive strength results of PET fibre modified concrete

The reduction of the compressive strength could be because of the smooth texture of the PET fibres in the mix which affects the bonding properties and adhesion of the concrete ingredient materials (Namakula, 2017).

c) Splitting Tensile Strength

The results for the splitting tensile test illustrate that increase of PET fibre content in concrete significantly increased splitting tensile strength (Figure 6). The highest splitting tensile strength of $3.327 \mathrm{MPa}$ was observed at $1.5 \%$ PET fibre addition by weight of cement. Mixes containing $0.5,1.0$ and $1.5 \%$ PET fibre by weight of cement exhibited a 7 th day splitting tensile increment of 5.31, 14.6, and $32.93 \%$, respectively, as compared to the control mix. The 28th day tensile strength also showed an increment of $6.58,14.72$ and $33.45 \%$ for $0.5,1.0$ and $1.5 \%$ PET fibre addition, respectively. Irwan et al. (2013) reported that the increase in the splitting tensile strength might be due to the bridging effect of the fibres across micro cracks. It took a longer time and more load for the specimens to fail. 


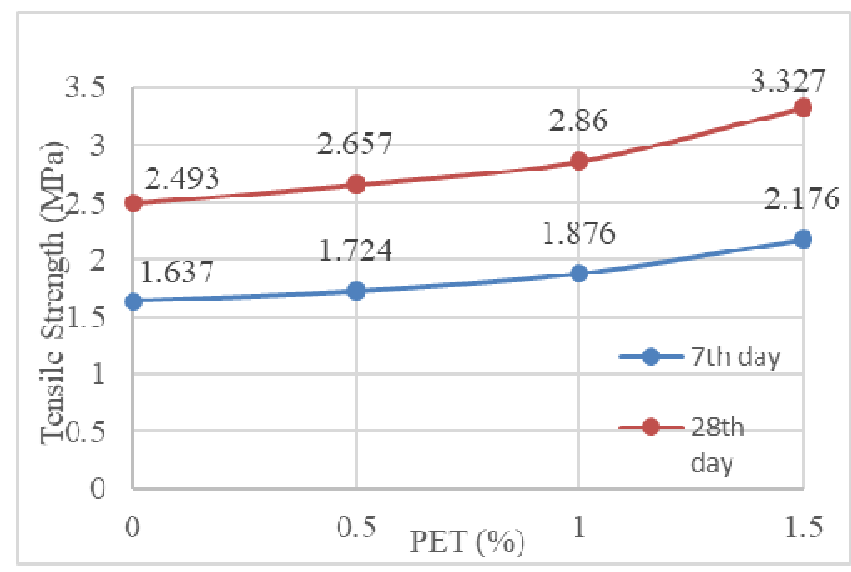

Figure 6: Tensile strength test results of PET fibre modified concrete

The results from the first section showed that $1.5 \%$ PET fibre addition to concrete, by weight of cement, gave the highest tensile strength. Therefore, $1.5 \%$ PET content was chosen as the optimum percentage from the first phase of the study. Although this percentage gave the maximum tensile strength, it also had the minimum compressive strength and workability at the same time. The addition of fly ash was to study if it would compensate for the compressive strength as well as the workability of the modified concrete. The second section was performed by keeping 1.5\% PET fibre content constant while replacing cement by five different percentages of fly ash content. Similar tests were repeated and the results compared to the $1.5 \%$ PET fibre modified concrete mix.

\section{d) Workability}

The slump test results show that workability significantly increases with increase in the proportion of fly ash replacing cement (Figure 7). A maximum slump of $90 \mathrm{~mm}$ was attained when $30 \%$ of cement by weight replaced fly ash. Compared to the $1.5 \%$ PET fibre modified concrete mix, the addition of $20,22.5,25,27.5$ and $30 \%$ fly ash increased workability by $160,200,350,720$, and $800 \%$, respectively.

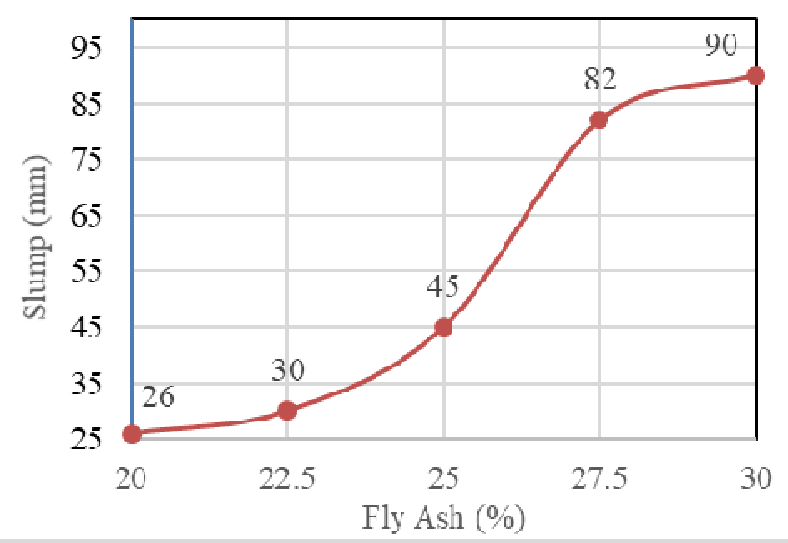

Figure 7: Workability results for PET fibre and fly ash modified concrete

This shows that partial replacement of cement by fly ash has a tendency to restore workability of concrete mix that was significantly reduced as a result of addition of PET fibres. According to Ramezanianpour (2014), if the fly ash is proportioned well in the concrete mixture, it improves the workability of the concrete due to its larger particles that take time to react completely with water. That is, at a given slump, concrete containing fly ash flows and consolidates better than the normal Portland cement concrete.

e) Compressive Strength

Compared to the $1.5 \%$ PET fibre modified concrete, the compressive strength of concrete replaced with 20, 22.5, $25,27.5$ and $30 \%$ fly ash increased by $9.23,12.25,12.77,17.07$ and $20 \%$ on the 7 th day and $9.75,13.26,14.08$, 18.46 , and, $21.99 \%$ on the 28 th day, respectively (Figure 8 ). The $27.5 \%$ cement replacement by fly ash restored the compressive strength of the mix to $25 \mathrm{MPa}$. Replacing $30 \%$ of cement by fly ash increased the compressive strength beyond $25 \mathrm{MPa}$. 


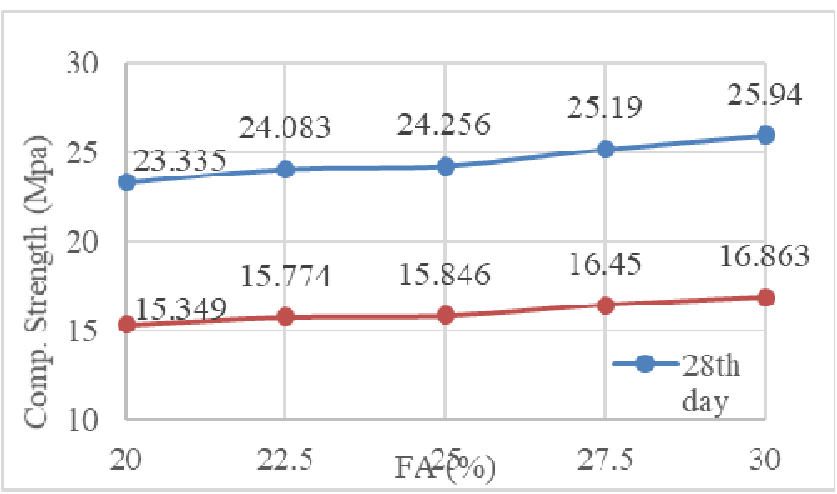

Figure 8: Compressive strength for PET fibre and fly ash modified concrete

This study revealed that due to its pozzolanic nature, the addition of fly ash to concrete as a partial cement replacement significantly contributes to the improvement of its compressive strength. Because of its larger and less reactive particles compared to Portland cement, fly ash continues the hydration reaction process up to six months. Although it does not develop the desired strength at early age, fly ash concrete increases the compressive strength as days go by. This is due to the continual hydration reaction of fly ash particles beyond 28 days (Harison et al., 2014; Reddy and Reddy, 2015; Joshi, 2017).

f) Splitting Tensile Strength

Splitting tensile strength test was conducted on all PET fibre and fly ash modified concrete mixes. The results show that the splitting tensile strength was not significantly affected by the addition of fly ash to the mix (Figure 9). The results show that compared to concrete modified with $1.5 \%$ PET, $27.5 \%$ cement replaced by fly ash gave a closer 28th day tensile strength value of 3.299 Mpa.

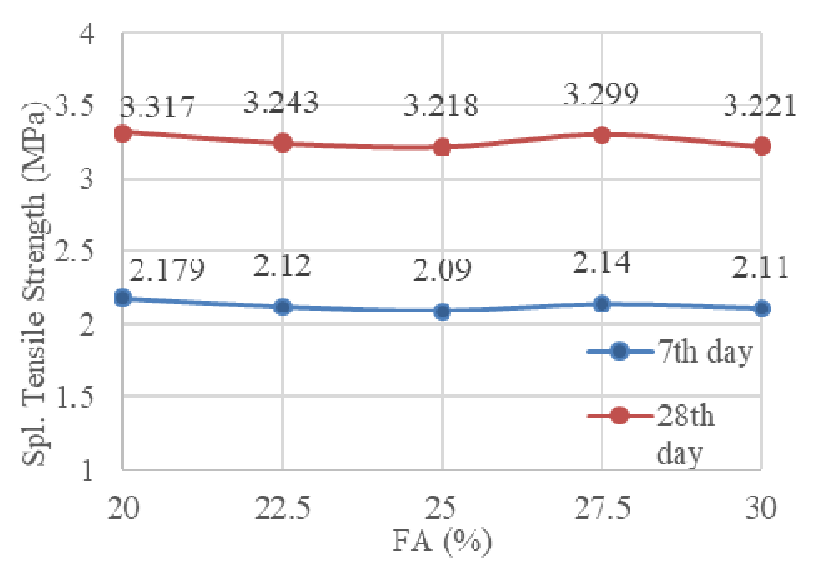

Figure 9: Tensile strength results for PET fibre and fly ash modified concrete

\section{Conclusions}

The following conclusions were drawn after studying the concrete modified with PET fibres and fly ash:

(i) Workability and compressive strength of the concrete mixes containing PET fibres decreased with the increase of fibre content.

(ii) Split tensile strength significantly increased with increase of PET fibre content.

(iii) Partial cement replacement of PET modified concrete by fly ash greatly improved workability as well as compressive strength of the concrete

(iv) Split tensile strength of PET modified concrete was not affected significantly by the partial cement replacement with fly ash.

(v) The combined effects of addition of PET fibres and partial cement replacement by fly ash improved the tensile strength of concrete while keeping its workability and compressive strength constant.

(vi) It is recommended to run more experimental tests on PET fibre and fly ash modified concrete in order to understand how its other properties are affected.

\section{References}

Ahmaruzzaman, M. (2010). A review on the utilization of fly ash. Progress in Energy and Combustion Science, 
36(3), 327-363

Akçaözoğlu, S., \& Atiş, C. D. (2011). Effect of Granulated Blast Furnace Slag and fly ash addition on the strength properties of lightweight mortars containing waste PET aggregates. Construction and Building Materials, 25(10), 4052-4058.

Akçaözoğlu, S., Atiş, C. D., \& Akçaözoğlu, K. (2010). An Investigation on the Use of Shredded Waste PET Bottles as Aggregate in Lightweight Concrete. Waste Management, 30(2), 285-290.

ASTM C1585. Standard Test Method for Measurement of Rate of Absorption ofWater by Hydraulic Cement Concretes; ASTM International: West Conshohocken, PA, USA, 2013.

Blissett, R.S., Rowson, N.A., 2012. A Review of the Multi-Component Utilization of Coal Fly Ash. Fuel 97, 123.

BS 1348-2, Test of Water for making Concrete, British Standards Institution, London, UK, 1980.

BS 1881-125. Testing Concrete- Part 125: Methods for Mixing and Sampling Fresh Concrete; British Standards Institution: London, UK, 2013.

BS 812-109. Testing aggregates -Part 109: Methods for determination of moisture content; BSI Standards Ltd.: London, UK, 1990.

BS 812-110. Testing aggregates- Part 110: Methods for determination of aggregate crushing value (ACV); BSI Standards Ltd.: London, UK, 1990.

BS 812-112. Testing aggregates- Part 112: Methods for determination of aggregate impact value (AIV); BSI Standards Ltd.: London, UK, 1990.

BS 882. Specification for Aggregates from Natural Sources for Concrete; BSI Standards Ltd.: London, UK, 1992.

BS 8500-2. Concrete Complementary British Standard to BS EN 206: Constituent Materials and Concrete; BSI Standards Ltd.: London, UK, 2012.

BS EN 1097-6. Tests for Mechanical and Physical Properties of Aggregates Part 6: Determination of Particle Density and Water Absorption; BSI Standards Ltd.: Brussels, Belgium, 2013.

BS EN 12350-1. Testing fresh concrete, Part 1: Sampling Fresh Concrete; BSI Standards Ltd.: London, UK, 2009.

BS EN 12350-2. Testing Fresh Concrete, Part 2: Slump Test; BSI Standards Ltd.: London, UK, 2009.

BS EN 12390-1. Concrete-Complementary British Standard to BS EN 206-1—Guidance for the Specifier; BSI Standards Ltd.: London, UK, 2012.

BS EN 12390-2. Testing Hardened Concrete, Part 2: Making and Curing Specimens for Strength Tests; BSI Standards Ltd.: London, UK, 2009.

BS EN 12390-3. Testing Hardened Concrete, Part3: Compressive Strength of Test Specimens; BSI Standards Ltd.: London, UK, 2009.

BS EN 12390-6. Testing Hardened Concrete, Part 6: Tensile Splitting Strength of Test Specimens; BSI Standards Ltd.: London, UK, 2009.

BS EN 12620. Aggregates for concrete; BSI Standards Ltd.: Brussels, Belgium, 2013.

BS EN 196-3. Methods of testing cement- Part 3: Determination of setting times and soundness; BSI Standards Ltd.: London, UK, 2016.

BS EN 197-1. Cement. Composition, specifications and conformity criteria for common cements; BSI Standards Ltd.: London, UK, 2011.

BS EN 206. Concrete Specification, Performance, Production and Conformity; British Standards Institution: London, UK, 2014.

BS EN 932-1. Tests for General Properties of Aggregates: Part 1. Methods for Sampling; Concrete Society: Farmington Hills, MI, USA, 1997.

BS EN 933-1. Tests for Geometrical Properties of Aggregates Part 1: Determination of Particle Size Distribution-Sieving Method; Concrete Society: Farmington Hills, MI, USA, 2012.

BS ISO 3310-2. Test Sieves-Technical Requirements and Testing Part 2: Test Sieves of Perforated Metal Plate; ISO: Geneva, Switzerland, 2013.

Fraternali F., Ciancia V., Chechile R., Rizzano G., Feo L. and Incarnato L. (2011), Experimental Study of the Thermo-Mechanical Properties of Recycled PET Fibre-Reinforced Concrete, Composite Structures, 93 (9), 2368-2374

Harison, A., Sricastava, V., \& Herbert, A., (2014), Effect of Fly Ash on Compressive Strength of Portland Pozzolona Cement Concrete, Journal of Academia and Industrial Research (JAIR), 2(8), 476-479

Irwan, J. M., Asyraf, R. M., Othman, N., Koh, K. H., Annas, M. M. K., \& Faisal, S. K. (2013), The Mechanical Properties of PET Fibre Reinforced Concrete from Recycled Bottle Wastes, Advanced Materials Research, 795, 347-351.

Izquierdo, M., Querol, X., 2012. Leaching Behavior of Elements from Coal Combustion Fly Ash: an overview. International Journal of Coal Geology, 94, 54-66. 
Joshi, R., (2017), Effect on Compressive Strength of Concrete by Partial Replacement of Cement with Fly Ash, International Research Journal of Engineering and Technology (IRJET), 4(2), 315-318

Kosmatka, A. W. (2011). Design and Control of Concrete Mixtures (Fifteenth). Portland Cement Association.

Namakula, H. (2017) Physical and Mechanical Experimental Investigation of Concrete incorporated with Polyethylene Terephthalate (PET) Fibres; European International Journal of Science and Technology, 6(8), $31-41$

Nibudey, R. N., Nagarnaik, P. B., Parbat, D. K., \& Pande, A. M. (2014). Compressive Strength and Sorptivity Properties of PET Fibre Reinforced Concrete. International Journal of Advances in Engineering \& Technology, 7(4), 1206-1216.

Ramezanianpour, A. A., (2014), Cement Replacement Materials: Properties, Durability, Sustainability, 1st ed., Springer Heidelberg, New York

Reddy, S. A. K., \& Reddy, K. C. (2015), Effect of Fly Ash on Strength and Durability Parameters of Concrete, International Journal of Science and Research (IJSR), 4(5), 1368-1370

Saini, K., Chaudhary, V., Bisnohi, A., Agarwal, H., Ram, M., \& Saraswat, S. (2016). Effect on Strength Properties of Concrete by Using Waste Wood Powder as Partial Replacement of Cement, 3(5), 172-176.

Standard Media, December 4th 2018: Kenya targets to recycle 14,000 tonnes of plastic bottles, Accessed June 18 , 2019 ; Nairobi,

Kenya: https://www.google.com/amp/s/www.standardmedia.co.ke/mobile/amp/article/2001305050/kenya-targetsto-recycle-14-000-tonnes-of-plastic-bottles

Van den Berg, S. (2014). Integration of the informal sector in PET bottle collection and recycling: South Africa, Ecuador, and Columbia, (June). Retrieved from http://www.waste.nl

Yao, Z. T., Ji, X. S., Sarker, P. K., Tang, J. H., Ge, L. Q., Xia, M. S., \& Xi, Y. Q. (2015). A comprehensive review on the applications of coal fly ash. Earth-Science Reviews, 141, 105-121. 